\title{
Developmental pattern of gene-specific DNA methylation in the mouse embryo and germ line
}

\author{
Tal Kafri, Mira Ariel, Michael Brandeis, Ruth Shemer, Lance Urven, ${ }^{1}$ John McCarrey, ${ }^{1}$ \\ Howard Cedar, and Aharon Razin \\ Department of Cellular Biochemistry, Hebrew University Medical School, Jerusalem, Israel; ${ }^{1}$ Department of Genetics, \\ Southwest Foundation for Biomedical Research, San Antonio, Texas 78228 USA
}

\begin{abstract}
Methylation patterns of specific genes have been studied by polymerase chain reaction and found to undergo dynamic changes in the germ line and early embryo. Some CpG sites are methylated in sperm DNA and unmodified in mature oocytes, indicating that the parental genomes have differential methylation profiles. These differences, however, are erased by a series of early embryonic demethylation and postblastula remodification events, which serve to reestablish the basic adult methylation pattern prior to organogenesis. During gametogenesis, all of these sites are unmethylated in primordial germ cells but eventually become remodified by 18.5 days postcoitum in both males and females. The final methylation profile of the mature germ cells is then formed by a multistep process of site-specific demethylation events. These results form a basis for the understanding of the biochemical mechanisms and role of DNA methylation in embryonic development.
\end{abstract}

[Key Words: Demethylation; methylation de novo; embryonic development]

Received December 2, 1991; revised version accepted February 25, 1992.

DNA methylation plays an important part in the process of gene regulation in somatic cells. Not only is there a clear correlation between gene expression and undermethylation, but transfection experiments clearly demonstrate that this modification acts as a repressor of transcription (Razin and Cedar 1991). Tissue-specific genes appear to be modified in almost all cell types and presumably undergo demethylation specifically in their tissue of expression. In contrast, housekeeping genes contain CpG islands that are unmethylated in all cells (Bird 1986). Thus, the methylation profile of the adult organism is probably descended from a single genomic pattern that is characterized by a combination of generalized methylation at nonisland $\mathrm{CpG}$ residues and constitutive hypomethylation at $\mathrm{CpG}$ islands.

It is not clear how this basic bimodal pattern of modification becomes established during early embryogenesis. Unlike somatic cells, which represent the end product of the differentiation process, cells in the germ line and early embryo serve as the founding precursors to the eventual adult organism. Thus, any changes in DNA methylation that occur at these stages must be corrected prior to the development of the soma. It is very possible that the genome undergoes significant alterations in its DNA methylation pattern in the embryo and germ line. Using a semiquantitative assay for overall DNA methylation, Monk et al. (1987) have already shown that total DNA from primordial germ cells, mature oocytes, and the blastua is relatively undermethylated. These initial studies also pointed out the interesting possibility that the methylation levels are lower in the oocyte than in sperm DNA, and this is supported by experiments on specific interspersed repeated sequence elements (Sanford et al. 1984, 1987).

Although these results indicate that DNA methylation may be in a state of flux during gametogenesis and early embryogenesis, they do not give any information about the extent of these changes or about the nature of the specific gene sequences that are undermethylated at these stages of development. For this reason, it has been difficult to assess the significance of this process. To generate an accurate picture of embryonic methylation profiles we have now employed a new polymerase chain reaction (PCR) methodology for assaying small quantities of DNA for the presence of methyl moieties at particular gene sites. In addition, we have also carefully probed the complicated ontogenic kinetics of DNA modification by examining a fairly representative number of different CpG loci at many different stages of development. This approach reveals a dramatic programmed process of gametic and embryonic methylation changes that is both stage specific and sequence specific. Furthermore, these data form the basis for understanding the general role of DNA methylation in the embryo and may shed light on its possible function in genomic imprinting. 
Kafri et al.

\section{Results}

Methylation assay

To follow the fate of specific methyl groups at different stages of embryo development, it was necessary to devise an assay sensitive enough for examining DNA from small numbers of cells. To this end, we adopted a new approach (Singer-Sam et al. 1990a,b) in which PCR technology provides the means for signal amplification. In this method, total cellular DNA is digested with methylsensitive enzymes, such as Hpall or HhaI, and specific fragments of DNA that contain these sites are amplified by flanking oligonucleotide primers. If a specific site is methylated, the amplification will proceed normally. On the other hand, the presence of an unmethylated site will result in digestion of the fragment and the subsequent failure to visualize the amplification product. When properly calibrated, this assay is linear over a wide range of DNA concentrations and can be used to accurately measure the degree of DNA methylation at specific sites (see Materials and methods). Examples of the methylation status of various gene loci in mature germ cells and during embryogenesis and gametogenesis are shown in Figures 2-5 (below). In addition, a summary of the modification states of all examined CpG sites is presented in Figure 6 (below).

DNA methylation state in mature germ cells

As a first step in studying the flow of DNA methylation patterns from the earliest stages of embryogenesis, it was necessary to evaluate the modification state of specific genes in mature germ cells. The methylation profile of many gene sequences in DNA has already been well documented (Yisraeli and Szyf 1984), but little is known about the methylation pattern of these same genes in mature oocytes. Using the PCR methodology, we have now assayed the methylation status of a number of HpaII and Hhal sites in and around various gene sequences in both sperm and oocyte DNA. These sites were chosen to represent both tissue-specific and housekeeping genes (see Fig. 1). In mature sperm DNA, every non-CpG island site that we examined was in a fully methylated state (Fig. 2), and this is consistent with previous results obtained from Southern blot hybridization analysis of a large variety of gene sequences (Yisraeli and Szyf 1984).

Many of the nonisland $\mathrm{CpG}$ residues also have a modified pattern in mature oocytes, but there are additional specific sites that are unmethylated, despite the fact that these same positions are fully methylated in sperm DNA. These included HpaII and Hhal sites at the $5^{\prime}$ end of the ApoAI and Pgk-2 gene, as well as single sites at the 3 ' end of APRT, Pgk-2, and the $\beta$ major globin gene (see Fig. 6, below). Thus, while the methylation patterns in the mature male and female germ cells share some common features, specific differences in modification clearly exist.

\section{Methylation patterns in the early embryo}

In the early embryo, the pattern of methylation inherited
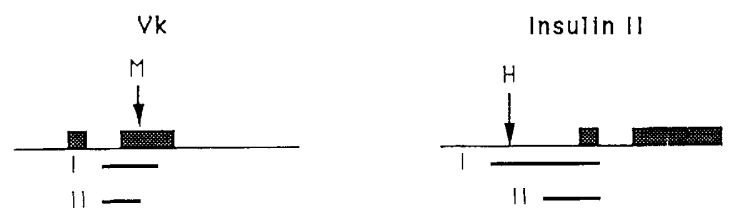

DHFR

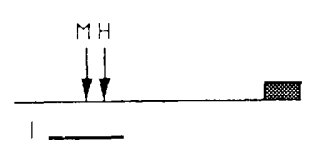

ApoAl
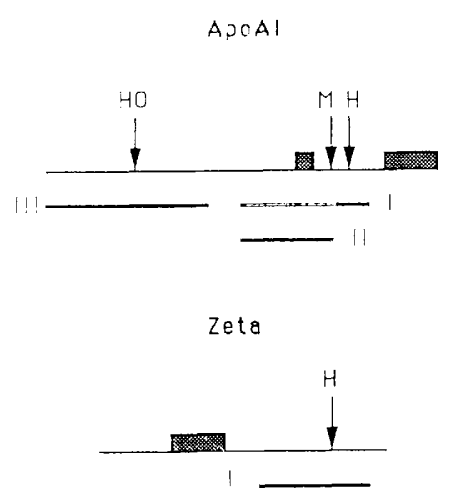

$1 \mathrm{~kb}$

Figure 1. Gene-specific CpG sites analyzed for methylation. Restriction maps of HpaII (M) and Hhal (H) sites in gene sequences used in this study are shown. The upstream HhaI site in ApoAI is designated as HO. Also indicated are the PCR amplification fragments containing these sites. Details of the oligonucleotide primers required to generate the PCR products are given in Materials and methods.

from the parental germ cells is rapidly lost, and by 16cell morulas, all tested CpG sites were found to have undergone demethylation (Figs. 3 and 6, below). This undermethylated state is retained through the blastula stage. Because $60 \%$ of the cells in these 3.5 -day embryos represent extraembryonic tissue (Hogan et al. 1986), this general undermethylation must be characteristic of both the inner cell mass and the extraembryonic cells. A number of sites have already undergone demethylation in eight-cell embryos, thus indicating that this process probably initiates before the first stages of trophectoderm differentiation.

Not all CpG loci undergo demethylation with the same kinetics. Sites that are modified in the sperm, but not in the ooctye DNA, undergo demethylation very rapidly and probably before the 8-cell stage, whereas those sites that are modified in both oocytes and sperm show a delayed demethylation that is completed at the 16-cell stage. If one assumes that mature oocytes still retain their ability to demethylate specific CpG sites, it is possible that these same loci, which are methylated in 

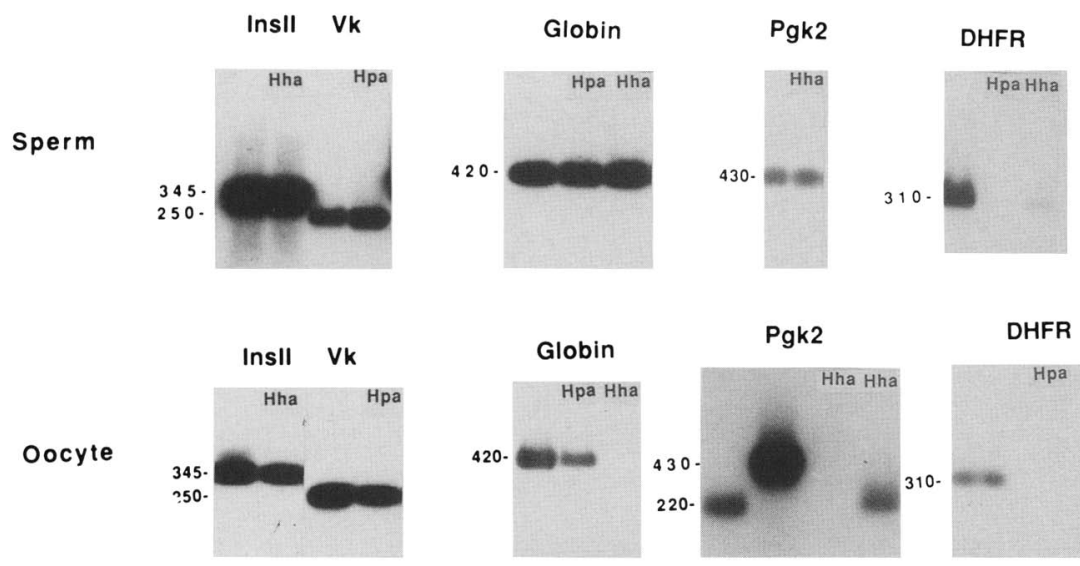

Figure 2. DNA methylation patterns in mature germ cells. DNA from either sperm or mature oocytes was digested with PvuII alone or together with HpaII or HhaI, and aliquots were amplified with specific sets of primers, electrophoresed, blotted, and hybridized to a probe made by labeling the same amplified fragment. For sperm and oocyte DNAs all amplifications were carried out on the same tissue preparation. The fact that some sites were found to be unmethylated served as a control for the completion of enzyme digestion. In addition, DNA samples were amplified in regions that do not contain $\mathrm{HpaII}$ or $\mathrm{HhaI}$ sites, and this provided a control to confirm that both digested and nondigested DNAs were present in similar quantities. One example of this is shown for the Pgk-2 gene in oocytes. In this case, the large fragment (430 bp) containing the HhaI site was amplified in the absence or presence of $H$ haI (the two internal lanes), and a similar experiment with the control fragment ( $220 \mathrm{bp})$ is shown in the two external lanes. In many cases, these experiments were performed in duplicate to verify the reproducibility of the assay method. An example of this is shown for the DHFR gene in oocytes where uncut and HpaII- or HhaI-cut DNAs were analyzed in duplicate. In the case of the insulin and $\mathrm{V}_{\mathrm{\kappa}}$ genes in sperm, both amplifications were run on the same gel, and the resulting blot hybridized with a mixture of both specific probes simultaneously. Both the sperm DNA and the oocyte DNA were prepared from pure populations of cells. In a control experiment we isolated granulosa cells and assayed their DNAs separately at the HpaII and Hhal sites at the $5^{\prime}$ end of the ApoAl gene (data not shown). While these sites were fully methylated in the granulosa cells, they were unmethylated in the oocyte, clearly indicating that these germ cell preparations were free of contamination.

sperm DNA, undergo rapid demethylation upon their exposure to the oocyte environment shortly after fertilization. Consistent with this hypothesis is the observation that the pattern of DNA methylation in eight-cell embryos is actually equivalent to that of the oocyte / see Fig. 6 , below). Other sites that are methylated in both germ lines may not be subject to this process and would then undergo a separate, delayed, demethylation reaction in 8to 16-cell embryos. Alternatively, sequences methylated

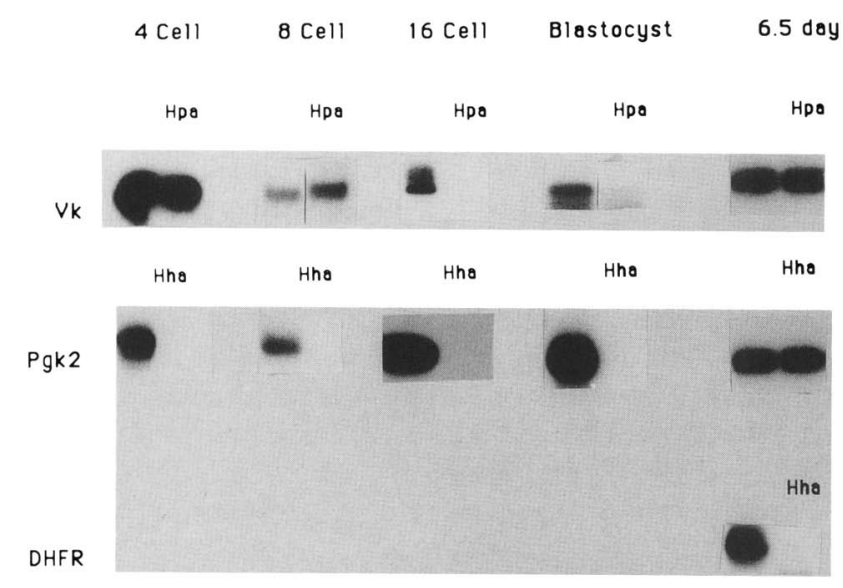

Figure 3. DNA methylation patterns in the early embryo. DNAs from various embryonic stages were digested with PvuII alone or together with HpaII or HhaI and then amplified with different gene-specific oligonucleotide primers. Visualization was by blot hybridization with specific probes. Shown are the results for $\mathrm{V}_{\mathrm{k}}$ and the $5^{\prime}$ Pgk-2 and DHFR Hha sites. The DHFR locus serves as a control to show that the DNA of 6.5-day embryos was digested. Some of the data on the methylation state of ApoAl in the early embryo can be seen in Shemer et al. (1991). in both alleles may simply require more time to reach a low level of modification, as measured by the PCR assay (see Materials and methods), especially if this process occurs by a passive replication-dependent mechanism.

CpG sites that were found unmethylated in the blastocyst become remethylated prior to gastrulation. In 6.5day embryos, almost all gene loci showed full modification except $\mathrm{CpG}$ island sequences, which apparently escape this wave of methylation (see Fig. 6, below). This pattern represents the modified form of the genome which, on one hand, serves as the prototype for the basic stable methylation pattern in somatic cells, and, at the same time, provides the template for specific demethylation events that occur during later stages of development.

\section{Establishment of methylation patterns during gametogenesis}

To understand how mature germ cells acquire their DNA methylation pattern, it was necessary to follow site-specific $\mathrm{CpG}$ modification changes during germ-line development. DNA from fetal germ cells at 12.5-13.5 days postcoitum (p.c.) was completely unmethylated at HpaII and HhaI sites from all tested gene sequences in both males and females. Thus, early germ cells retain the same modification pattern found in the 3.5-day blastula (Figs. 4 and 6, below). However, this apparent escape from the generalized de novo methylation that occurs early on in somatic cells is only temporary, as a similar process of remodification subsequently takes place in germ cells during late fetal stages in both males and females. The delay in the gamete remethylation process may be related to the fact that germ cells migrate from 
Kafri et al.

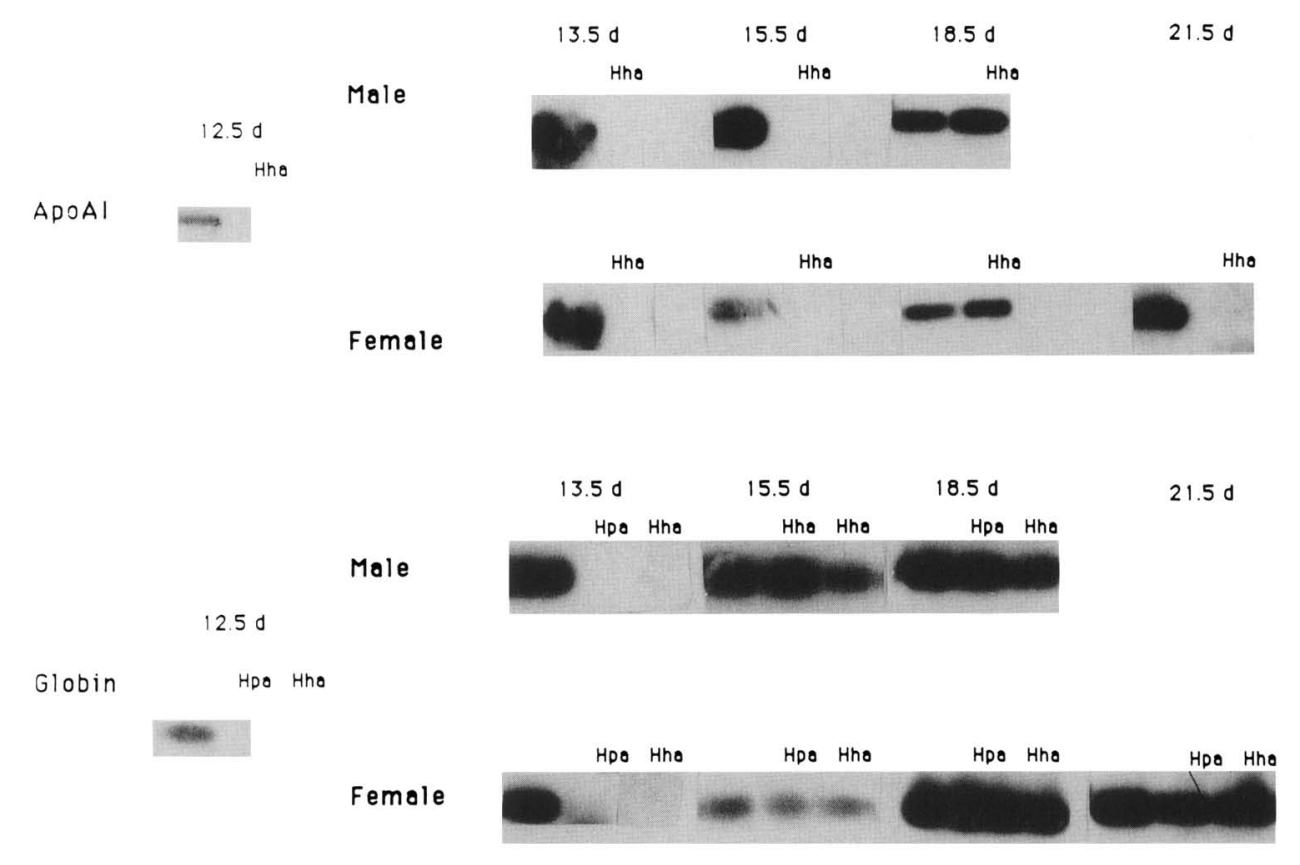

Figure 4. DNA methylation patterns in embryonic germ cells. DNAs ( $1 \mathrm{ng}$ ) from different stages of germ line development in males and females were purified and digested with PvuII alone or together with HpaII or HhaI and then amplified with either the ApoAl (fragment I) or $\beta$-globin-specific oligonucleotide primers. Visualization was by blot hybridization with specific probes. The uncut sample for globin in female 18.5-day germ cells is shown in duplicate. For each stage, control experiments were performed to verify the presence of equal quantities of DNA in cut and uncut samples. HpaII and HhaI in DHFR were unmethylated at every stage and thus served as a digestion control. This widespread undermethylation seen in primordial cells was apparently unique to the germ cells, as both ApoAl and $\beta$-globin were found to be methylated in fetal liver tissue from 12.5- and 13.5-day embryos. To show that the total undermethylation seen in 12.5- and 13.5-day primordial germ cells is not the result of some artifact, these DNAs were treated with HpaII and Hhal methylases and then shown to become resistant to digestion (data not shown).

the epiblast into the yolk sac, where they remain sequestered until they start making their way to the newly forming embryonic gonads. Some CpG sites in germ cells become modified by 15.5 days p.c., but remethylation only reaches completion by 18.5 days p.c., when the pattern of modification becomes identical to that of typical somatic cell DNA.

In the male germ line, most sites remain fully methylated both in the fetal and adult testis, but CpG loci at the $5^{\prime}$ end of the ApoAl and Pgk-2 genes undergo demethylation at some point prior to 6-day primitive type-A spermatogonia (Figs. 4 and 5). This pattern of methylation then remains stable during all stages of spermatogenesis in the testis, including pachytene spermatocytes, round spermatids, and testis sperm (Fig. 5; Ariel et al. 1991). A further round of de novo methylation presumably takes place at the final stages of sperm maturation in the epididymis, thus remodifying all remaining non-CpG island residues. During oogenesis, the same sites in ApoAl and Pgk-2 also undergo a specific demethylation reaction, which is completed by 21.5 days p.c. A second round of demodification involving gene loci at the $3^{\prime}$ end of APRT, Pgk-2, and $\beta$-globin occurs during the period of ooctye maturation prior to ovulation. In contrast to these specific demethylated sites, CpG moieties in other tissue-specific genes appear to remain fully modified throughout the process of oocyte development.

\section{Discussion}

\section{Demethylation in the early embryo}

The data presented here demonstrate, at the level of specific gene sites, that the DNA methylation pattern of the mouse undergoes dynamic and widespread alterations during gametogenesis and embryogenesis. At fertilization, the genome of the mouse is clearly made up of paternal and maternal components, which have different methylation patterns. While all the non-CpG island sites examined in this study are methylated in sperm DNA, many of these loci are unmethylated in the mature oocyte. This situation is rapidly altered by a two-step programmed process of demethylation that takes place in the early embryo. All of the sites that we examined by PCR analysis were completely unmethylated at the morula and blastula stages of development, and this indicates that the demethylation process must involve both the paternal and maternal genome. Definitive proof that this is the case was obtained by showing that a paternally derived human ApoAl transgene also became unmethylated in early mouse embryos (Shemer et al. $1991 \mathrm{~b}$.

Initial studies had already indicated that the overall level of methylation is relatively low in the blastula (Monk et al. 1987) but did not define the extent of undermethylation or the nature of the sequences involved. 


\section{Spermat Pach Round Testis \\ ogonia Spcy Sptid Sperm}

ApoA1

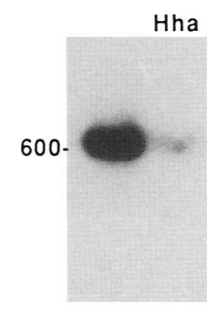

Hha Hha Hha

600

Spermatogonia

Pachytene spermatocytes

Round spermatids

Globin

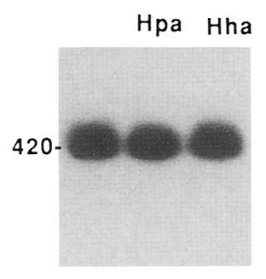

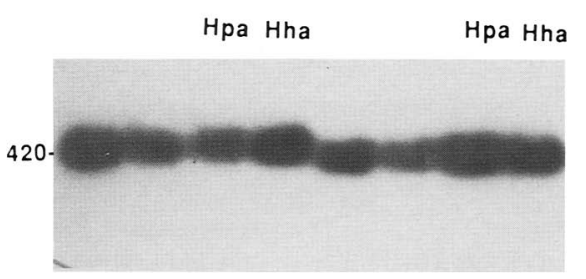

Figure 5. DNA methylation patterns during spermatogenesis in adult testis. Methylation analysis was performed as described in the legend to Fig. 4. For the globin gene in pachytene spermatocytes and round spermatids the PvuII-digested control DNA was amplified in duplicate. It should be noted that all of the CpG loci described in Fig. 6 were also analyzed at these stages of spermatogenesis and showed a pattern identical to that obtained for spermatogonia.
Our results on specific CpG sites in representative gene loci clearly show that a large fraction of the genome must be totally unmethylated at this stage, and this includes genes that are thought to be expressed only in specific somatic cell types. Despite this clear-cut pattern, it would be premature to conclude that every CpG site in the genome is unmethylated; further experiments with additional DNA sequences will be required to clarify the specificity of this process. It should be noted that several interspersed repeated sequences also undergo demethylation in the early embryo (Sanford et al. 1987; Howlett and Reik 1991) and thus behave similarly to the sites examined in our study. Satellite DNA, which contains $>40 \%$ of all the CpG residues in the mouse is known to be relatively undermethylated in both sperm and ooctye (Chapman et al. 1984; Ponzetto-Zimmcrman and Wolgemuth 1984), but its modification state in the early embryo has not yet been investigated.

What is the biological significance of early embryonic demethylation? It is possible that demodification of the genome and its subsequent remethylation provide a mechanism for removing differences in specific gene methylation patterns that emerge from the male and female germ lines to allow initiation of the normal program of embryonic development. The timing of the initial demethylation appears to coincide with activation of zygotic transcription (McLaren 1976; Clegg and Piko 1983). DNA methylation is known to have profound effects on both chromatin structure and gene expression (Cedar and Razin 1990). Thus, there is no question that this massive undermethylation, encompassing a major part of the genome, may influence the physiology of the embryo. Because DNA methylation represents one of the cellular mechanisms for the global suppression of gene activity, it is possible that many somatic genes become partially derepressed in the blastula. A phenomenon of this nature has been described in Xenopus embryos, where several genes, including myoD, are constitutively expressed following the midblastula transition (Rupp and Weintraub 1991).

\section{Reestablishment of the somatic methylation pattern}

The de novo methylation that we observed at specific CpG sites in a representative sample of endogenous genes in pregastrula-stage embryos is clearly a reflection of a general genome-wide remodification. This is probably the same activity that is responsible for de novo modification of exogenous viral sequences and transgenes that have been artificially introduced into the early embryo (Jahner and Jaenisch 1984). The finding that almost all sites are modified at this early stage of development provides experimental proof for the existence of a basic ubiquitous modification pattern, which serves as a template for subsequent tissue-specific demethylation events.

The mechanism for this reconstitution is not known, but its specificity may be based on the ability of the organism to recognize CpG island DNA. In the case of both endogenous genes and transgenes (Kolsto et al. 1986; Shemer et al. 1990, 1991a,b; Frank et al. 1991) this is the only class of sequence to remain unmethylated in 6.5- to 8-day embryos and in somatic cells of the mature organism. A CpG island-specific demethylation reaction has been described recently, and this activity is uniquely present in embryonic cell lines (Frank et al. 1991; Shemer et al. 1991a). In combination with a nonspecific general de novo methylation system, a CpG island-spe- 
cific factor of this nature could lead to the selective protection of island sequences and thereby play a role in directing the reestablishment of the normal somatic modification pattern. Thus, although the basic genome methylation pattern must be rebuilt in every individual, the rules for achieving this may be quite simple. Whatever the mechanism, however, it must also take into consideration the special class of $\mathrm{CpG}$ island-containing housekeeping genes on the inactive $\mathrm{X}$ chromosome that actually undergo de novo methylation following their inactivation at the blastula stage (Singer-Sam 1990a; Lock et al. 1987).

\section{Formation of the gametic methylation patterns}

We have shown that mouse fetal germ cells at 12.5-13.5 days p.c. are unmethylated at all tested CpG sites and thus carry an overall modification pattern similar to that seen in the morula and blastula. Studies by Driscoll and Migeon (1990) using 8- to 21-week human embryos also suggested a relative undermethylation in germ cells, but this conclusion was derived from experiments with relatively impure cell populations and involved the analysis of mainly $\mathrm{X}$-linked genes that are probably undergoing reactivation during these stages of development. The pathway by which primordial germ cells become hypomethylated has not been investigated. One possibility is that these cells escape the de novo methylation that occurs just prior to gastrulation and thus retain the early embryonic modification pattern. A mechanism of this type could be consistent with the fact that early germ cells migrate from the primitive ectoderm to the yolk sac and remain sequestered there before entering the fetal gonads at 11-12 days p.c. Alternatively, DNA in germ cells may initially undergo de novo methylation together with somatic cells but then become demethylated again prior to 12.5 days p.c. In any event, it appears that early primordial germ cells must retain the ability to demethylate DNA, because at least one imprinted transgene has been shown to erase its methylation pattern at this stage of development (Chaillet et al. 1991).

Monk et al. (1987) have suggested previously that there is a basic difference between methylation kinetics in the male and female germ cells. While the male genome was thought to undergo de novo methylation at late stages of germ-line development, the female genome was assumed to remain undermethylated throughout oogenesis. Although this proposed pattern is consistent with their data, these investigators did not examine a sufficient number of time points to confirm the kinetics. By analyzing DNA methylation at frequent time intervals of gametogenesis in the mouse, we have shown that de novo methylation actually occurs in germ-line cells in both males and females in an apparently time-dependent manner that is completed by 18.5 days in both sexes (Fig. 6). This modification reaction is not strictly linked to sex-specific germ-cell differentiation, because at this stage, male germ cells are still undergoing mitotic divisions, whereas in the female, most cells have already entered meiotic prophase (McLaren 1984). In light of these results it appears that germ-cell differentiationspecific demethylation events are all derived from the basic bimodal genomic modification pattern in a manner similar to that which occurs in somatic cells.

The methylation patterns observed in mature gametes are determined by several major events during the late stages of germ cell differentiation. For example, demethylation at the $5^{\prime}$ end of the Pgk-2 and ApoAl loci occurs in both male and female germ cells (Fig. 6, group B). Because both genes are specifically transcribed during spermatogenesis (McCarrey and Thomas 1987; Walsh et al. 1989), demodification at these particular loci is most likely related to their expression in the testis and, in the case of Pgk-2 demethylation, is known to take place before the onset of its expression (Ariel et al. 1991). It is not clear, however, why these genes also undergo methylation changes at about the same time during oogenesis. A second round of demodification is sex specific and takes place in meiotic cells during germ cell maturation in the female. It is not yet known why these particular loci undergo demethylation, but it is interesting that all of the sites are located at $3^{\prime}$ positions (Fig. 6, group C). Because a final round of site-specific remodification only occurs in the male, it is these two demethylation events that are responsible for the differential undermethylated state of the female germ line. The final stages of oocyte maturation occur in only a small population of ovary cells. For this reason, and because of limitations in the PCR method, it is not clear whether the methylation changes during this period take place in all oocytes or are linked to the process of maturation. In any event, the fact that demethylation occurs in meiotic cells provides strong evidence that the demodification events associated with oogenesis all occur through an active enzymatic process that is not dependent on DNA replication.

\section{Implications for genomic imprinting}

Specific mouse endogenous genes have been shown to have parentally imprinted expression patterns (Barlow et al. 1991; Bartolomei et al. 1991; DeChiara et al. 1991). In addition, genomic imprinting has been described in some strains of transgenic mice; and in these cases, there is a correlation between the parental source of a gene and its state of methylation in the adult animal (Monk 1988). If DNA modification actually serves as the primary signal that dictates imprinted patterns of expression, it is necessary, but not sufficient, to demonstrate that specific imprinted genes have different methylation profiles in sperm and mature ooctyes. Although several $\mathrm{CpG}$ sites of this nature have been observed in our study, these particular modification differences were all erased at an early stage of development and none of these genes are known to be imprinted. We have examined only a limited number of DNA loci and it is thus possible that genuine imprinted genes do have differential methylation patterns that are stably maintained throughout embryogenesis. This is clearly the case for the maternally inactivated Tg.RSVIgmycA transgene, which has a unique pattern of methylation kinetics during embryo- 


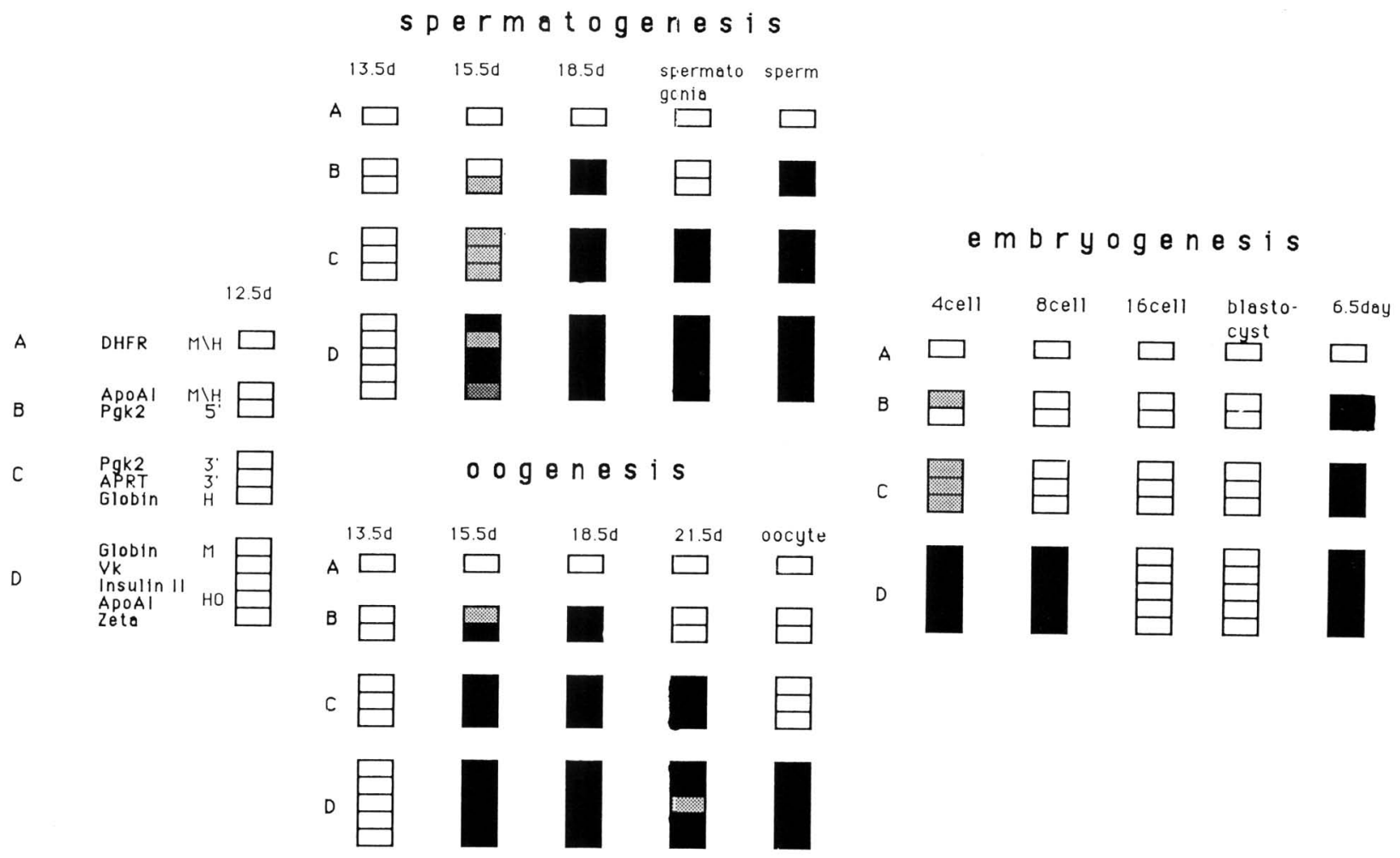

Figure 6. Developmental patterns of DNA methylation in the embryo and germ line. The results of the PCR assay on a wide selection of gene-specific CPG sites are displayed diagrammatically. Open boxes indicate $<10 \%$ methylation at the specific site; solid boxes indicate $50-100 \%$ modification. Partial methylation $(20-50 \%)$ is indicated by a stippled box. Genes are divided into four groups. Group A contains two sites in the DHFR CpG island that were unmethylated in every DNA sample tested; group B contains all genes that become demethylated in both male and female germ-line cells; genes in group C are only demethylated in the female; group D represents specific gene sites that are methylated in both sperm and mature oocytes. Eight-day embryos have the same pattern as 6.5-day embryos. Using standard blot hybridization analysis it was shown that several of the sites in 8-day embryos are fully methylated in both alleles (data not shown). Some of the data relating to the ApoAl gene in the early embryo have been published (Shemer et al. 1991b). It should be noted that all of the results shown here were derived from direct PCR assays on every CpG site at all of the different stages of development as described in Figs. 2-5.

genesis. Specific sites in this construct are unmethylated in sperm DNA and methylated in the oocyte, and this maternal allele then remains modified through blastulation. It is clear from these results that DNA modification serves to mark the maternal allele during oogenesis, and this may play a role in the subsequent imprinting process. Because most gene sequences undergo demethylation in the early embryo, one must propose that elements in the imprinted allele are again recognized at the morula and blastula stages and are thereby prevented from undergoing demethylation. Using the methodology developed in our study, it should now be possible to follow the fate of endogenous imprinted genes and thus decipher the role of DNA methylation in this process.

\section{Materials and methods}

Preparation of DNA

Mouse sperm DNA from the ductus deferens was prepared as described previously (Ariel et al. 1991). Oocytes were collected from oviducts of F1C57 black $\times$ BALB/c unmated females that were treated for superovulation by intraperitoneal injection of 4
I.U. of PMSG (pregnant mare serum gonadotropin) followed 48 hr later by $5 \mathrm{I}$.U. of HCG (human chorionic gonadotropin). Twenty hours after the second injection, ooctyes were collected into PBS containing $1 \mathrm{mg}$ of hyaloronidase and $10 \mathrm{mg} / \mathrm{ml}$ of polyvinylpyrolidone (PVP). Oocytes were rinsed in this solution by repeated suctioning into a drawn-out pipette to remove granulosa cells attached to the oocytes. To remove the zonae pelucida, oocytes were washed in acidic tyrode solution and transferred immediately into PBS (Hogan et al. 1986). DNA from $\sim 200$ oocytes was extracted in $150 \mathrm{~mm} \mathrm{CaCl}_{2}, 15 \mathrm{~mm}$ Tris- $\mathrm{HCl}$ (pH 7.4), $3 \mathrm{~mm}$ EDTA, $0.4 \%$ SDS, $70 \mathrm{mg} / \mathrm{ml}$ of proteinase $\mathrm{K}$, and $20 \mathrm{mg} / \mathrm{ml}$ of pancreatic RNase at $37^{\circ} \mathrm{C}$ in the presence of $5 \mu \mathrm{g}$ of ФX DNA and further purified by phenol-chroloform extraction and $\mathrm{EtOH}$ precipitation.

Four-, 8-, and 16-cell embryos were removed from oviducts of mated superovulated females at 52,64, and $70 \mathrm{hr}$ after HCG injection, respectively, and rinsed several times by suction into a drawn-out pipette in F-10 (HAM) plus $10 \%$ FCS medium and once in PBS. This material was collected and kept at $-20^{\circ} \mathrm{C}$ until enough material was available for DNA preparation. Blastocysts were collected by flushing the uteri of mated superovulated females 3.5 days p.c. as described above for very early embryos. Each sample was mixed with $\Phi \mathrm{X}$ carrier DNA $(5 \mu \mathrm{g})$ and extracted as described above. 
Late primordial germ cells from both male and female fetal gonads at 12.5 days p.c., oogonia from fetal ovaries at 13.5 days p.c., and type-M prospermatogonia from fetal testes at 13.5 days p.c. were all isolated by antibody-directed flow sorting as described previously (McCarrey et al. 1987). Briefly, fetal gonads were dissected from ICR mice (Sprague-Dawley) and cells were dissociated using trypsin plus EDTA. The dissociated cells were then incubated with a germ cell-specific monoclonal antibody, EMA-1 (Hahnel and Eddy 1986), at $0.5 \times$ concentration, and then with a fluoresceinated (5-fluorescein isothiocyanate) goat antimouse secondary antibody, and sorted on a fluorescence-activated cell sorter (FACS). Purities of germ cells in the recovered populations were assessed on the basis of alkaline phosphatase activity, an independent histochemical marker for fetal germ cells at this stage of development. For this study, the purity of germ cells in the recovered populations was consistently $\geqslant 90 \%$.

Cell populations enriched for leptotene/zygotene oocytes, pachytene oocytes, and diplotene oocytes were obtained from fetal ovaries at 15.5 days p.c., 18.5 days p.c., and 21.5 -days p.c., respectively (Borum 1961; McLaren 1988), whereas type- $T_{1}$ prospermatogonia were obtained from fetal testes at 15.5 days p.c. and 18.5 days p.c. and type- $\mathrm{T}_{2}$ prospermatogonia were obtained from fetal testes at 21.5-day p.c. (Burgoyne 1987). Note that the 21.5-day p.c. oocytes may have included some follicles that had initiated the growth phase. These cells were isolated by unit gravity sedimentation (Romrell et al. 1976 ) using a $50-\mathrm{ml}$ "mini" Sta Put apparatus. Briefly, gonads were dissected from ICR mouse fetuses, decapsulated in the cases of 18.5 - and 21.5 day p.c. testes, and dissociated using trypsin plus EDTA as described above. Dissociated cells were then layered over a $2-4 \%$ gradient of BSA plus $0.1 \%$ PVP and allowed to sediment for $2-4$ $\mathrm{hr}$ at $4^{\circ} \mathrm{C}$. The gradient was fractionated into $\sim 100$ fractions 10.5 $\mathrm{ml}$ each) from which aliquots were analyzed by phase microscopy to identify germ cell-rich fractions on the basis of cellular morphology and size. This procedure yielded populations enriched to $85-95 \%$ purity for each germ cell type. Primitive type-A spermatogonia were isolated from testes of 6-day-old CD-1 mice (Charles River) using a 550-ml "small" Sta Put apparatus as described previously (Bellve et al. 1977). Pachytene spermatocytes, round spermatids, and testis sperm were isolated as described previously (Romrell et al. 1976). The percentage of germ cells in these preparations was assessed by phase microscopy and found to be $85-95 \%$.

DNA was prepared from each population of germ cells by incubation with proteinase $\mathrm{K}$ in the presence of SDS as described previously (Ausubel et al. 1990). This was followed by phenol-chloroform extraction and ethanol precipitation. After resuspending the precipitated DNA in $1 \times$ TE $10.01 \mathrm{M}$ Tris at $\mathrm{pH}$ $8.0,0.001 \mathrm{M}$ EDTA), the samples were drop dialyzed through a Millipore $0.025-\mu \mathrm{m}$ filter against $0.1 \times$ TE for $2-6 \mathrm{hr}$.

\section{PCR methylation analysis}

DNA from each cell type was divided into three aliquots that were digested, respectively, with PvuII alone, PvuII + HpaII, and PvuII + HhaI. Each sample was amplified in a volume of 50 $\mu \mathrm{l}$ at a dNTP concentration of $0.2-1 \mathrm{mM}$ with one set of oligonucleotide primers $(0.2 \mu \mathrm{M}$ each $)$ and subsequently electrophoresed, blotted, and hybridized either to a cloned plasmid probe $\left\langle V_{k}\right.$, globin, ApoA1, Pgk-2, $\left.\zeta\right\}$ or to a probe made with the same specific primers (insulin, DHFR, APRT). To obtain reliable amplification results, this rcaction was calibrated to yield a visible product with a minimum number of cycles. Each cycle was programmed to $1 \mathrm{~min}$ incubation at $94^{\circ} \mathrm{C}, 2 \mathrm{~min}$ at $55^{\circ} \mathrm{C}$, and 3 min at $72^{\circ} \mathrm{C}$, except for the first two cycles in which denaturation was carried out for $4 \mathrm{~min}$. In the case of most DNA sam- ples, amplification was carried out for 22-25 cycles using $1 \mathrm{ng}$ of DNA (100 cell equivalents). For oocytes, morulas, and blastocysts, reactions were usually carried out with only $50-100 \mathrm{pg}$ of DNA using 30-35 cycles. Under these conditions, the amount of visualized product was linear over a 50-fold range of DNA concentrations. In addition, we tested mixtures of cut and uncut DNA to assess the accuracy of measuring the degree of methylation. These preliminary studies showed that one cannot easily distinguish between $50-100 \%$ methylation. On the other hand, the assay yielded quite accurate results when the degree of methylation was $<15 \%$. DNA from every tissue sample was digested with PvuII alone or together with HpaII or HhaI. These three aliquots were then used to test every $\mathrm{CpG}$ site in the survey. Because DHFR is constitutively unmethylated and has sites for both HpaII and HhaI, this gene served as a control for enzyme digestions. For many of the loci we also prepared primers for assaying regions that lack HpaII or HhaI sites (Fig. 1), and one or two of these were always used to ensure that each aliquot contained an equal amount of DNA. For almost all of the sites examined we ascertained that the PCR products were correct. Hybridization was confirmed with a plasmid gene clone, and the product obtained from genomic DNA was digested with several enzymes known to be characteristic of the given PCR fragment. In addition, only one band always appeared on the blots and its molecular size was as expected.

\section{PCR primers}

We analyzed one Hpall site in the second exon of the $\mathrm{V}_{\mathrm{\kappa}}$ gene using fragment $I / 5^{\prime}$ primer, TGTGATGACCCAGTCTCA; 3 ' primer, AACTGCTAGGTCTTCAGC). A control fragment (II) that does not contain the HpaII site was made with the same $5^{\prime}$ primer and an alternate $3^{\prime}$ primer (GGATGCCGAATAAATCAG). In the insulin II gene an HhaI site flanking the $5^{\prime}$ end of the first exon was analyzed using fragment I $15^{\prime}$ primer, GCCCCTTGTTAAGACTCT; 3' primer, GAGGCTATATCC TACCTCl. Control fragment II, which lacks the HhaI site was amplified using the same $3^{\prime}$ primer and an alternate $5^{\prime}$ primer (ATAAAGGTAGT GGGGACC). The HpaII and Hhal sites in the DHFR domain are located in the 5' $\mathrm{CpG}$ island, which was analyzed using fragment $I\left(5^{\prime}\right.$ primer, GAAGCACCAAGACCTCAA; 3' primer, GAGAAGGTAAAGTACGGC). In the mouse $\beta$ major globin gene we studied the methylation of HpaII and HhaI sites located $3^{\prime}$ to the last exon using fragment $\mathrm{I} / 5^{\prime}$ primer, TCATACCATGCCTGCACAGT; 3' primer, ACTGTACCA GAGAGTAGCGT). Three different fragments were used to an alyze sites in and around the ApoAl gene. HpaII and HhaI sites in the first intron were studied using fragment $I / 5^{\prime}$ primer, GATGGTGCAACTGCCTTA; 3' primer, ATTCTGTTCTCTGTGCCC). The control fragment (II) had a common 5' primer and a different $3^{\prime}$ primer (CTCTTCTTCCCTGGTCTA). A second region farther upstream contained an $\mathrm{HhaI}$ site $(\mathrm{H} 0)$, which was analyzed using fragment III $\left(5^{\prime}\right.$ primer, CTGACCTTCCAAGTGCAA; 3' primer, GATGCAGACAGGCTCATA). For the Pgk-2 gene we analyzed one HhaI site within the gene sequence and a second located $3^{\prime}$ to the gene using fragment I $15^{\prime}$ primer, TATTCATTAGAGCCTGTTGC; $3^{\prime}$ primer, GTCTTTCACTTTGGCTCCAC), a control fragment (II) made with the same $3^{\prime}$ primer and an alternate $5^{\prime}$ primer (TAGAAGCCTTCCGAGCATCA $)$, and fragment III $\left(5^{\prime}\right.$ primer, GGTGTAAAGATAGTTTTTCC; 3' primer, ATTTTACCTTCCAGAAGCTC). We analyzed one Hhal site in the first intron of the T-cell receptor $\zeta$ gene (Baniyash et al. 1989) using fragment I. The HpaII site in the fourth exon of the mouse APRT gene was analyzed with fragment I (5' primer, ACTCTGGAGTATGGGAAGGT; 3' primer, GAGGAGGTGTTCAAGCTCTT). 
Primer sequences for $V_{\kappa}$ were obtained from Y. Bergman (Hebrew University), those for $\zeta$ from M. Baniyash (unpubl.), and the remainder from the GenBank library.

\section{Acknowledgments}

We thank Y. Bergman and M. Baniyash for providing sequence data needed to prepare oligonucleotide primers. We are also grateful to E.M. Eddy for generously providing EMA-1 antibody, to J. Flook for tcchnical expertise in running the FACS, and to N. Laufer for introducing us to the techniques of oocyte and early embryo preparations. This research was supported by $\mathrm{Na}$ tional Institutes of Health $(\mathrm{NIH})$ research grants (H.C., A.R., and J.M.), the Council for Tobacco Rescarch (USA) (A.R. and H.C.), an NIH career development award (J.M.), and grants from the Israel Cancer Research Fund (H.C.) and the U.S.--Israel Binational Science Foundation (H.C.). We also acknowledge support from the Tom Slick Molecular Biology Fellowship (L.U.) and the Foulkes Foundation Fellowship (T.K.).

The publication costs of this article were defrayed in part by payment of page charges. This article must therefore be hereby marked "advertisement" in accordance with 18 USC section 1734 solely to indicate this fact.

\section{References}

Ariel, M., J. McCarrey, and H. Cedar. 1991. Methylation patterns of testis-specific genes. Proc. Natl. Acad. Sci. 88: 2317-2321.

Ausubel, F.M., R. Brent, R.E. Kingston, D.D. Moore, J.G. Scidman, J.A. Smith, and K. Struhl. 1990. Current protocols in molecular biology. Wiley/Greene, New York.

Baniyash, M., V.W. Hsu, M.F. Seldin, and R.D. Klausner. 1989. The isolation and characterization of the murine $T$ cell antigen receptor $\zeta$ chain gene. J. Biol. Chem. 264: 1325213257.

Barlow, D.P., R. Stoger, B.G. Herrmann, K. Saito, and N. Schweifer. 1991. The mouse insulin-like growth factor type- 2 receptor is imprinted and closely linked to the Tme locus. Nature 349: 84-87.

Bartolomei, M.S., Z. Sharon, and S.M. Tilghman. 1991. Parental imprinting of the mouse H19 gene. Nature 351: 153-155.

Bellve, A.R., J.C. Cavicchia, C.F. Millette, D.A. O'Bricn, Y.M. Bhatnagar, and M. Dym. 1977. Spermatogenic cells of the prepuberal mouse, isolation and morphological characterization. I. Cell Biol. 74: 68-85.

Bird, A.P. 1986. CpG-rich islands and the function of DNA methylation. Nature 321: 209-213.

Borum, K. 1961. Oogenesis in the mouse. Exp. Cell Res. 24: 495-507.

Burgoyne, P.S. 1987. The role of the mammalian Y chromosome in spermatogenesis. Development (Suppl.) 101: 133-141.

Cedar, H. and A. Razin. 1990. DNA methylation and development. Biochim. Biophys. Acta 1049: 1-8.

Chaillet, J.R., T.F. Vogt, D.R. Beier, and P. Leder. 1991. Parentalspecific methylation of an imprinted transgene is established during gametogenesis and progressively changes during embryogenesis. Cell 66: 77-83.

Chapman, V., L. Forrester, J. Sanford, N. Hastie, and J. Rossant. 1984. Cell lincage-specific undermethylation of mouse repetitive DNA. Nature 307: 284-286.

Clegg, K.B. and L. Piko. 1983. Poly(A) length, cytoplasmic adenylation and synthesis of poly $|A|^{+}$RNA in early mouse embryos. Dev. Biol. 95: 331-341.
DeChiara, T.M., E.J. Robertson, and A. Efstratiadis. 1991. Parental imprinting of the mouse insulin-like growth factor II gene. Cell 64: 849-859.

Driscoll, D.J. and B.R. Migeon. 1990. Evidence that human single copy genes which are methylated in male meiotic cells are unmethylated in female meiotic germ cells and fetal germ cells of both sexes. Somatic Cell Genet. 16: 267-275.

Frank, D., I. Keshet, M. Shani, A. Levine, A. Razin, and H. Cedar. 1991. Demethylation of CpG islands in embryonic cells. Nature 351: 239-241.

Hahnel, A.C. and E.M. Eddy. 1986. Cell surface markers of mouse primordial germ cells defined by two monoclonal antibodies. Gamete Res. 15: 25-34.

Hogan, B., F. Constantini, and E. Lacey. 1986. Manipulating the mouse embryo: A laboratory manual. Cold Spring Harbor Laboratory, Cold Spring Harbor, New York.

Howlett, S.K. and W. Reik. 1991. Methylation levels of maternal and paternal genomes during preimplantation development. Development 113: 119-127.

Jahner, D. and R. Jaenisch. 1984. DNA methylation in early mammalian development. In DNA methylation: Biochemistry and biological significance (ed. A. Razin, $\mathrm{H}$. Cedar, and A.D. Riggs), pp. 189-219. Springer-Verlag, New York.

Kolsto, A.B., G. Kollias, V. Giguere, K.I. Isobe, H. Prydz, and F. Grosveld. 1986. The maintenance of methylation-free is lands in transgenic mice. Nucleic Acids Res. 14: 9667-9678.

Lock, L.F., N. Takagi, and G.R. Martin. 1987. Methylation of the Hprt gene on the inactive $\mathrm{X}$ occurs after chromosome inactivation. Cell 48: 39-46.

McCarrey, J.R. and K. Thomas. 1987. Human testis-specific PGK gene lacks introns and possesses characteristics of a processed gene. Nature 326: 501-505.

McCarrey, J.R., K.C. Hsu, E.M. Eddy, R.R. Klevecz, and J.L. Bolen. 1987. Isolation of viable mouse primordial germ cells by antibody-directed flow sorting. I. Exp. Zool. 242: 107111.

McLaren, A. 1976. Genetics of the early mouse embryo. Annu. Rev. Genet. 10: 361-388.

. 1984. Meiosis and differentiation of mouse germ cells. In 38th Symp. of Soc. for Exp. Biol. "Controlling events in meiosis" (ed. C.W. Evans and H.G. Dickinson), pp. 7-23. Company of Biologists, Cambridge, UK.

- 1988. The developmental history of female germ cells in mammals. Oxf. Rev. Reprod. Biol. 10: 162-179.

Monk, M. 1988. Genomic imprinting. Genes \& Dev. 2: $921-$ 925.

Monk, M., M. Boubelik, and S. Lehnert. 1987. Temporal and regional changes in DNA methylation in the embryonic, ex traembryonic and germ cell lineages during mouse embryo development. Development 99: 371-382.

Ponzetto-Zimmerman, C. and D.J. Wolgemuth. 1984. Methylation of satellite sequences in mouse spermatogenic and somatic DNAs. Nucleic Acids Res. 12: 2807-2822.

Razin, A. and H. Cedar. 1991. DNA methylation and gene expression. Microbiol. Rev. 55: 451-458.

Romrell, L.J., A.R. Bellve, and D.W. Fawcett. 1976. Separation of mouse spermatogenic cells by sedimentation velocity. A morphological characterization. Dev. Biol. 49: 119-131.

Rupp, R.A.W. and H. Weintraub. 1991. Ubiquitous MyoD transcription at the midblastula transition precedes inductiondependent MyoD expression in presumptive mesoderm of $\mathrm{X}$ laevis. Cell 65: 927-937.

Sanford, I., L. Forrester, V. Chapman, A. Chandley, and N. Hastie. 1984. Methylation patterns of repetitive DNA sequences in germ cells of Mus musculus. Nucleic Acids Res. 12: 2823-2836. 
Kafri et al.

Sanford, J.P., H.J. Clark, V.M. Chapman, and J. Rossant. 1987. Differences in DNA methylation during oogenesis and spermatogenesis and their persistence during early embryogenesis in the mouse. Genes \& Dev. 1: 1039-1046.

Shemer, R., A. Walsh, S. Eisenberg, J.M. Breslow, and A. Razin. 1990. Tissue specific expression and methylation of the human apolipoprotein A1 gene. J. Biol. Chem. 265: 1010-1015.

Shemer, R., S. Eisenberg, J.L. Breslow, and A. Razin. 1991a. Methylation patterns of the human apoAI-CIII-AIV gene cluster in adult and embryonic tissue suggest dynamic changes in methylation during development. $/$. Biol. Chem. 266: 23676-23681.

Shemer, R., T. Kafri, A. O'Connell, S. Eisenberg, J.L. Breslow, and A. Razin. 1991b. Methylation changes in the apoAI gene during embryonic development of the mouse. Proc. Natl. Acad. Sci. 88: 11300-11304.

Singer-Sam, J., M. Grant, J.M. LeBon, K. Okuyama, V. Chapman, M. Monk, and A.D. Riggs. 1990a. Use of a HpaII-polymerase chain reaction assay to study DNA methylation in the Pgk-1 CpG island of mouse embryos at the time of X-chromosome inactivation. Mol. Cell. Biol. 10: 4987-4989.

Singer-Sam, J., J.M. LeBon, R.L. Tanguay, and A.D. Riggs. 1990b. A quantitative HpaII-PCR assay to measure methylation of DNA from a small number of cells. Nucleic Acids Res. 18: $687-692$.

Walsh, A., Y. Ito, and J.L. Breslow. 1989. High levels of human apolipoprotein A-I in transgenic mice result in increased plasma levels of small high density lipoprotein (HDL) particles comparable to human $\mathrm{HDL}_{3}$. I. Biol. Chem. 264: 64886494.

Yisraeli, J. and M. Szyf. 1984. Gene methylation patterns and expression. In DNA methylation: Biochemistry and biological significance (ed. A. Razin, H. Cedar, and A.D. Riggs), pp. 352-370. Springer-Verlag, New York. 


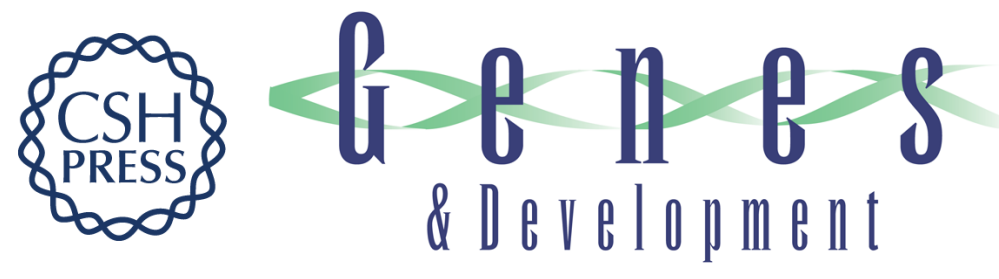

\section{Developmental pattern of gene-specific DNA methylation in the mouse embryo and germ line.}

T Kafri, M Ariel, M Brandeis, et al.

Genes Dev. 1992, 6:

Access the most recent version at doi:10.1101/gad.6.5.705

References This article cites 37 articles, 14 of which can be accessed free at:

http://genesdev.cshlp.org/content/6/5/705.full.html\#ref-list-1

License

Email Alerting

Service

Receive free email alerts when new articles cite this article - sign up in the box at the top right corner of the article or click here.

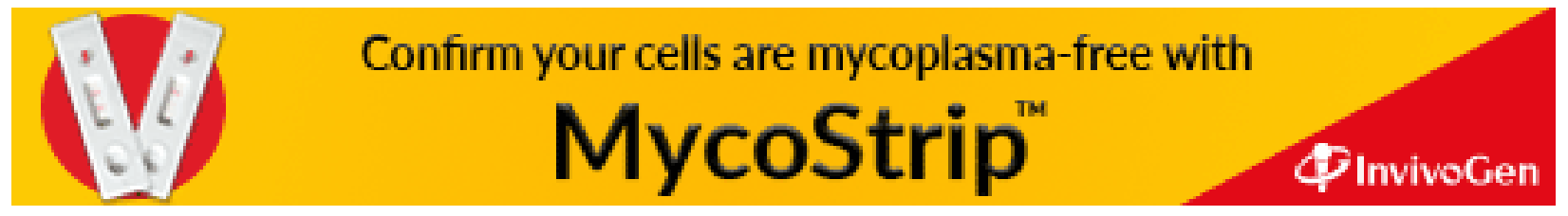

